\title{
Protagonismo infantil: um estudo no contexto de instituições dedicadas à educação da primeira infância em Bolonha
}

\section{Child protagonism: a study in the context of institutions dedicated to early childhood education in Bologna}

\author{
Bianca Salazar Guizzo* \\ Lucia Balduzzi** \\ Arianna Lazzari**
}

\begin{abstract}
RESUMO
Neste artigo, nosso objetivo é pensar sobre alguns modos como o protagonismo de crianças vinculadas à educação infantil tem sido potencializado a partir dos espaços a elas disponibilizados e a partir da atuação docente junto a elas. Para tanto, foram realizadas observações em instituições educacionais da cidade de Bolonha (Itália) que atendem exclusivamente crianças pequenas. Além disso, foram consultados alguns materiais de divulgação das suas propostas pedagógicas. Analiticamente, operamos - em especial - com os conceitos de Pedagogia da Infância e de Pedagogia do Cotidiano (OLIVEIRA-FORMOSINHO e FORMOSINHO, 2007; BARBOSA, 2010; CARVALHO e FOCHI, 2016; 2017). Os resultados apontaram que tanto a organização do espaço como a atuação das docentes das escolas observadas incentivam a construção da autonomia e da independência das crianças, ou seja, elas são as principais protagonistas de seus processos de desenvolvimento e de aprendizagem.
\end{abstract}

Palavras-chave: Educação infantil. Protagonismo. Pedagogia da infância. Pedagogia do cotidiano.

* Universidade Luterana do Brasil. Programa de Pós-Graduação em Educação. Porto Alegre, Rio Grande do Sul, Brasil. E-mail: bguizzo_1@hotmail.com. http://orcid.org/0000-0003-1080-2210.

** Universidade de Bolonha. Bologna, Italia. E-mail: lucia.balduzzi2@unibo.it. http:// orcid.org/0000-0002-3934-9416. E-mail: arianna.lazzari2@unibo.it http://orcid.org/0000-0001$6710-4515$. 


\begin{abstract}
In this article, our objective is to consider some ways in which the protagonism of children linked to early childhood education has been enhanced through the spaces available to them, and the teaching activity in which they are integrated. As such, educational institutions in the city of Bologna (Italy) that exclusively attend small children were the subjects of observation. In addition, some materials publicizing their pedagogical proposals were consulted. Analytically, we particularly operate with the concepts of an Everyday Life (OLIVEIRA-FORMOSINHO et al., 2007; BARBOSA, 2010; CARVALHO e FOCHI, 2016; 2017). The results indicated that, in the observed schools, both spacial organization and teacher performance encourage the construction of autonomy and independence in the children, i.e., they are the main protagonists of their own development and learning processes.
\end{abstract}

Keywords: Early childhood education. Protagonism. Pedagogy as related to childhood. Pedagogy of everyday life.

\title{
Introdução
}

Contemporaneamente, as crianças pequenas (de até cinco anos) têm ganhado protagonismo em diferentes âmbitos, dentre os quais podemos destacar: o educacional, o investigativo, o publicitário etc. No Brasil, a educação formal voltada para essas crianças, ou seja, a educação infantil, tem sido amplamente discutida, questionada e problematizada (ROSEMBERG, 2009, 2014; CAMPOS, 2010; CAMPOS e BARBOSA, 2016). Especialmente a partir do final do século XX, no Brasil, "a Educação Infantil passou a construir uma nova identidade, buscando superar o caráter meramente assistencial ou preparatório para as etapas posteriores de escolarização" (GUIZZO e FELIPE, 2012, p. 630).

Foi a partir da Constituição Federal Brasileira de 1988 que a educação das crianças de zero a seis anos passou a ser direito social de todos/as e dever do Estado. Tal direito foi reiterado no Estatuto da Criança e do Adolescente (Lei 8.069/1990) e na Lei de Diretrizes e Bases da Educação Nacional (Lei 9.394/1996), que legalmente passou a denominar a educação infantil como primeira etapa da educação básica. Outros documentos, como o Referencial Curricular Nacional para a Educação Infantil (1998) e as Diretrizes Curriculares Nacionais para a Educação Infantil (2010), por exemplo, são expressões claras da direção que as políticas educacionais assumiram no Brasil com relação à Educação Infantil. Em 2005, a Lei 11.114 alterou a redação dada à Lei 
de Diretrizes e Bases da Educação Nacional e tornou obrigatório o ingresso no Ensino Fundamental aos seis anos. Em 2006, a Lei 11.274/2006 ampliou o ensino fundamental para nove anos e tornou obrigatória a inclusão da criança de seis anos neste nível de ensino (CORREA, 2011). Em função dessa lei, foi aprovada a Emenda Constitucional n. ${ }^{\circ}$ 53, de 2006, que redefiniu a faixa etária compreendida no atendimento da educação infantil para zero a cinco anos. Em 2009, por meio da Emenda Constitucional n. ${ }^{\circ}$ 59/2009, propôs-se a obrigatoriedade de inserção das crianças de quatro anos em instituições de ensino formais. Em 2013, essa obrigatoriedade consolidou-se a partir da Lei Federal 12.796/2013. Alguns estudos têm, de certo modo, criticado a forma como são desenvolvidas as propostas pedagógicas junto a essas crianças, uma vez que se enfatiza a questão da alfabetização e do letramento de maneira intensa (MOSS, 2016; SUBRAMANIAN, 2015; TAGGART, SYLVA, MELHUISH, SAMMONS, BLATCHFORD, 2011).

Alguns documentos, tal como os Parâmetros Nacionais de Qualidade para a Educação Infantil (2006), têm procurado destacar justamente o contrário, ou seja, explicitam que para favorecer o crescimento e o desenvolvimento das crianças não é preciso inseri-las precocemente em processos de alfabetização, mas é preciso incentivá-las, apoiadas em suas próprias iniciativas e ancoradas em estratégias pedagógicas em que elas sejam as protagonistas, a: movimentar-se livremente em diferentes espaços, brincar; expressar sentimentos e pensamentos; desenvolver a imaginação, a curiosidade e a capacidade de expressão.

Embora até aqui tenha sido feita uma retomada a respeito da maneira como a educação infantil veio sendo proposta no Brasil especialmente até 2016, neste artigo o principal propósito é pensar sobre alguns modos como o protagonismo de crianças vinculadas à educação infantil tem sido potencializado em decorrência dos espaços a elas disponibilizados e a partir da atuação docente junto a elas, tomando como referência o contexto italiano, mais especificamente escolas de educação infantil da cidade de Bolonha. Analisar e problematizar tal contexto torna-se relevante uma vez que, segundo Finco, Barbosa e Faria (2015, p. 8), as escolas infantis italianas têm possibilitado uma experiência de infância enriquecida, na medida em que atentam tanto para os "[...] modos de escutar, observar e compreender as crianças", quanto para "[...] vozes comprometidas com a organização de escolas, com experiências de gestão escolar [...] que pretendem colocar de ponta-cabeça e transformar visando a melhoria da qualidade de vida das crianças, das suas famílias e comunidades [...]".

Para dar conta dessas questões, este texto está organizado da seguinte forma: 1) discutimos o modo como entendemos o "protagonismo infantil", articulando-o a dois conceitos: Pedagogia da Infância e Pedagogia do Cotidiano; 2) situamos o leitor tanto sobre o local onde realizamos a pesquisa, quanto sobre 
os aspectos metodológicos empreendidos; 3) apresentamos os resultados analíticos problematizando especialmente a forma como a organização do espaço e a atuação das docentes das escolas observadas incentivam a construção da autonomia e da independência das crianças; 4) traçamos algumas considerações finais.

\section{Teia de conceitos: protagonismo infantil articulado à Pedagogia da Infância e à Pedagogia do Cotidiano}

A palavra "protagonismo" tem origem no latim: protos quer dizer principal e agonistes significa lutador. Ser protagonista é ter papel de destaque num acontecimento, área ou situação. No campo da Educação, pode-se dizer que o conceito de protagonismo emergiu a partir das discussões propostas pelos escolanovistas ${ }^{1}$. Atualmente, é possível afirmar que esse conceito ressurge com bastante força, principalmente em referenciais educacionais italianos que remetem a um entendimento de "criança competente e curiosa, sociável e forte, e ativamente ocupada na criação da experiência e na construção da identidade e do conhecimento" (MOSS, 2009, p. 419).

$\mathrm{Na}$ contemporaneidade, as crianças são reconhecidas como sujeitos de direitos, capazes de construir conhecimentos e potencialmente participantes. $\mathrm{O}$ protagonismo infantil vincula-se à participação efetiva das crianças no seu desenvolvimento, bem como na (re)solução de situações e de problemas que emergem no cotidiano em que estão inseridas, sob supervisão e/ou orientação dos adultos com quem convivem. Ou seja, ele opera a favor de uma lógica que tem como propósito a formação de sujeitos infantis que sejam "proativos, inovadores, inventivos, flexíveis, com senso de oportunidade, com notável capacidade de promover mudanças" (GADELHA, 2013, p. 156).

Para que esse protagonismo ocorra é imprescindível que uma certa liberdade (atrelada às ideias de autonomia e independência) seja colocada em prática. Entretanto, conforme Barbosa e Quadros (2017, p. 47): “É preciso não apressar, não acelerar, não entrar na lógica capitalista, mas oferecer tempo para as crianças aprenderem e apreenderem-se no mundo interagirem e construírem as suas culturas infantis (BARBOSA, 2007; BARBOSA, 2014)".

$1 \mathrm{O}$ movimento escolanovista refere-se a um conjunto de ideias que se contrapõem à educação tradicional que emergiu entre o final no século XIX e o início do século XX. Dentre as ideias desse movimento está o foco no ensino democrático. Tais ideias reverberam ainda hoje nas práticas pedagógicas, por exemplo: currículo por projetos, preocupação com o interesse da criança, discursos sobre a liberdade dos educandos. 
A discussão sobre protagonismo infantil proposta neste artigo pode ser potencializada a partir de dois conceitos importantes que vêm sendo pensados por outros estudiosos do campo da Educação Infantil. Um deles é o conceito de Pedagogia da Infância (OLIVEIRA-FORMOSINHO, 2007; BARBOSA, 2010); o outro é o de Pedagogia do Cotidiano (CARVALHO e FOCHI, 2016; 2017).

Oliveira-Formosinho (2007) destaca a insistência do fazer pedagógico que muitas vezes ainda ignora os direitos da criança de ser vista como capaz e a ter espaço de participação. Em razão disso, discute sobre o entendimento de Pedagogia da Infância baseada em uma práxis de participação infantil. Segundo essa autora, a Pedagogia da Infância consiste num espaço de interações orientadas para projetos colaborativos em circunstâncias que promovam a participação não somente do corpo docente, mas principalmente das crianças. Para tanto, aspectos como a observação, a escuta e a negociação são fundamentais "para desenvolver um fazer e um pensar pedagógico que fogem à fatalidade" (OLIVEIRA-FORMOSINHO, 2007, p. 29).

De acordo com Barbosa (2010) o entendimento de Pedagogia da Infância critica a reprodução de modelos educativos reducionistas e conservadores e respalda-se num "conjunto de fundamentos e indicações de ação pedagógica que tem como referência as crianças e as múltiplas concepções de infância em diferentes espaços educacionais". A mesma autora argumenta que, com base na Convenção dos Direitos da Criança (1989), a Pedagogia da Infância considera que as crianças são sujeitos de direitos, sendo assim é imprescindível a definição de experiências pedagógicas que oportunizem às crianças viver a infância de maneira que sejam priorizados projetos educacionais baseados "na democracia, na diversidade, na participação social, a partir de práticas educativas que privilegiem as relações sociais entre todos os segmentos envolvidos (crianças, familiares e educadores)" (BARBOSA, 2010).

Conforme Carvalho e Fochi (2017, p. 25), o entendimento de Pedagogia do Cotidiano dialoga com o de Pedagogia da Infância, uma vez que também emerge "das relações, indagações, investigações, proposições, mediações e descobertas que se realizam na vida diária das crianças na educação infantil". Os mesmos autores argumentam que Pedagogia do Cotidiano pode ser entendida como:

1) uma forma de entender que as crianças aprendem pela via da vida cotidiana, por meio "dos encontros, atividades, dificuldades e sucessos, a partir de um repertório de práticas” (BROUGÈRE, 2012, p. 17); 2) um modo de valorização e de promoção da miríade de experiências vivenciadas por meninos e meninas na vida diária da escola; 3) uma potente 
possibilidade de construir indicadores para a ação pedagógica na creche e na pré-escola que tomem como eixos norteadores do planejamento as interações, as brincadeiras e as maneiras peculiares como as crianças investigam, experimentam e constroem conhecimentos sobre si, sobre os outros e sobre o mundo; 4) uma "tradução" dos pressupostos teóricos da pedagogia da infância (Barbosa, 2010) em modos inteligíveis de atuação dos professores [...]. (CARVALHO e FOCHI, 2017, p. 25-6).

Enfim, é a partir da vivências e situações do dia a dia que são oportunizadas às crianças que tornem possível o protagonismo delas nos seus próprios processos de desenvolvimento. E nosso objetivo é justamente discutir como a organização do espaço e a atuação docente potencializam esses processos. Antes, porém, de trazer essa discussão, apresentaremos algumas informações sobre o modo como a educação infantil vem sendo pensada e estruturada na cidade de Bolonha, bem como sobre o modo como os dados empíricos analisados neste artigo foram produzidos.

\section{Educação Infantil em Bolonha}

Como este artigo problematiza a questão do protagonismo infantil a partir de observações realizadas em instituições de educação infantil localizadas na cidade italiana de Bolonha, é importante compreender como essa etapa da educação foi se constituindo nessa cidade. É fato que, nas últimas décadas, a discussão sobre a educação e os cuidados na primeira infância conquistaram uma posição de destaque em diferentes partes do mundo, incluindo a Europa. Inicialmente essa discussão deveu-se, em especial, às preocupações com o emprego das mulheres e a igualdade de oportunidades.

Na região de Emília Romana, cuja capital é Bolonha, as instituições de Educação Infantil tiveram sua origem na década de 1960, por iniciativa de grupos de mulheres e por movimentos democráticos (CATARSI, 2004). As primeiras instituições eram de cunho privado e tinham um viés educacional religioso (especialmente católico). O principal objetivo dessas instituições era suprir as necessidades de crianças inseridas em famílias menos favorecidas economicamente. Seus pressupostos baseavam-se nos das Irmãs Agazzi, cuja ideia de ser professora era vista como uma vocação e/ou um chamado. Ser docente era visto como um ato de maternagem, razão pela qual originou-se o nome "escola materna" (LAZZARI, 2012). 
Da década de 1960 em diante um maior investimento público, no Centro e Norte da Itália, é observado no que diz respeito à educação da primeira infância. Diferente das escolas privadas, as escolas públicas procuravam levar a cabo valores antifascistas, primando por aspectos como: paz, democracia, solidariedade, equidade de oportunidades. Além disso, iniciou-se um processo cujos seguintes aspectos ganharam força: envolvimento da comunidade; participação das famílias; trabalho docente valorizado como profissional, valorização da cultura infantil e ênfase no educar e no cuidar.

Segundo Lazzari (2017), especialmente nas décadas de 1980 e 1990, a região de Emília Romana assumiu um papel pioneiro na sustentação da inovação dos serviços, a fim de tornar a educação infantil mais sensível às necessidades das crianças e de suas famílias por meio de uma organização integrada, diferenciada e flexível. O setor público desempenhou um papel ativo e relevante no apoio às experiências locais desenvolvidas com crianças pequenas, a partir da criação de redes e de formações que reforçavam a cultura pedagógica elaborada nas instituições de educação infantil, o que - de certo modo - constituiu uma experiência de vanguarda (BALDUZZI, 2006). Mantovani e Musatti (1996) afirmam que, a partir dos anos de 1990, novos serviços (centros para crianças e genitores, espaço infantil e pequenos grupos educativos) foram experimentados procurando atender às necessidades emergentes de responsáveis e de crianças.

Por fim, cabe mencionar que atualmente a educação das crianças de zero a seis anos não é obrigatória na região de Emília Romana. As crianças de até três anos frequentam o que, em italiano, nomeia-se de Nido. As maiores, de três a seis anos, frequentam a Scuola dell'Infanzia. Embora a frequência a esses níveis de educação não seja obrigatória, o percentual de crianças que os frequenta é bastante alto, ou seja, mais de $90 \%$ das crianças têm oportunidade de acesso.

Contemporaneamente importantes discussões vêm sendo empreendidas em função de uma nova perspectiva colocada pelo "Sistema Integrado de Educação e Instrução do nascimento até os seis anos", definida pela Lei 107/2015 e pelo Decreto 65 de 2017. A partir desses ordenamentos normativos, o Nido (educação de zero a três anos) e a Scuola dell'Infanzia (educação de três a seis anos) passam a compor um sistema integrado, já que até pouco tempo o Nido era responsabilidade do Ministério da Saúde e Assistência Social e a Scuola del'Infanzia, do Ministério da Educação (ZUCCOLI e INFANTINO, 2018). Tais ordenamentos, segundo Zuccoli e Infantino (2018, p. 16), redimensionam, a partir de uma nova perspectiva, a educação de zero a seis, ao mesmo tempo que trazem significativos desafios, especialmente no que tange "à coordenação e aos processos de formação profissional dos educadores e professores". 


\section{Aspectos metodológicos}

O material empírico que problematizamos neste artigo, a partir de um viés qualitativo de análise, é decorrente de pesquisa de campo realizada em três instituições que atendem crianças de zero a seis anos de idade na cidade de Bolonha/Itália, sendo duas públicas e uma privada ${ }^{2}$. Uma delas atende crianças de zero a três anos, outra atende crianças de quatro a seis anos e a última atende crianças de zero a seis anos. Todas localizam-se em bairros periféricos de Bolonha e o público que atendem é de origem tanto estrangeira como italiana. Os responsáveis pelas crianças formam casais mistos (um italiano e um estrangeiro), casais italianos e casais estrangeiros. Devido à diversidade étnica e cultural existente nas instituições, há uma variedade de línguas maternas faladas pelas crianças, dentre elas: línguas árabes, latinas, anglo-saxãs etc. Entretanto procura-se empreender nas escolas a comunicação em italiano.

Para que, enquanto pesquisadoras, fosse possível o nosso acesso às escolas, todos os trâmites burocráticos e autorizações necessários foram seguidos/ adquiridos. Inicialmente, enviamos uma mensagem, via correio eletrônico, ao departamento responsável chamado Istituzione Educazione e Scuola Giovanni Sedioli da Comune di Bologna, solicitando o agendamento de visitas e a realização de observações. Dias depois recebemos o aceite da nossa solicitação e nos dias agendados fomos recebidas pela coordenadora da região à qual pertencem as instituições visitadas. Durante nossa permanência nas instituições conversamos com a coordenadora pedagógica, tivemos acesso a documentos, visitamos todos os ambientes que compõem os espaços físicos das instituições, efetuamos registros fotográficos desses espaços, bem como realizamos registros escritos em um Caderno de Anotações.

Para acesso à escola privada também fizemos uma solicitação formal através de envio de mensagem eletrônica. Prontamente obtivemos o aceite e a informação de que poderíamos estar na escola ao longo de três dias. Durante a nossa estada nessa instituição também tivemos a oportunidade de conhecer os espaços, de conversar com as professoras e com as coordenadoras pedagógicas, de acompanhar algumas propostas desenvolvidas e a rotina de turmas compostas por crianças de diferentes faixas etárias. Além disso, tivemos acesso à consulta de alguns documentos que explicitavam as propostas das escolas e os serviços oferecidos por elas.

2 Importante esclarecer que as instituições públicas visitadas são municipais (ou seja, gerenciadas pela Instituição Escolar e Infantil). Na Itália, há também jardins de infância estatais, que compõem a maioria dos serviços frequentados por crianças de 3 a 6 anos, entretanto esses estabelecimentos não foram visitados. 


\section{Organização do espaço e docência como propulsoras do protagonismo infantil}

De acordo com Galardini (2017), a pedagogia de instituições que atendem crianças pequenas necessita ter como princípio a função de acompanhá-las em seu desenvolvimento. Sendo assim, precisam propor práticas que possibilitem não só o bem-estar, mas estimulem o protagonismo e a autonomia das crianças. Os Parâmetros Nacionais de Qualidade para a Educação Infantil (2006) salientam que, para favorecer o crescimento e o desenvolvimento das crianças, é necessário que elas sejam apoiadas em suas tarefas cotidianas e espontâneas. A organização das escolas observadas em Bolonha, bem como a atuação das docentes a elas vinculadas mostraram-se alinhadas a propostas que vêm sendo defendidas também no Brasil, como é o caso dos Parâmetros mencionados.

Numa manhã fria de inverno as crianças de 2 e 3 anos foram convidadas a ir para o pátio externo. Numa recepção que dá acesso à rua havia uma estante (Figura 1) onde estavam todos os sapatos, já que - ao chegarem na escola - eles são tirados e substituídos por meias pelo fato de o piso ser aquecido. Cada uma delas foi incentivada a localizar seus sapatos, bem como a calçá-los (Caderno de Anotações, 29/01/2018).

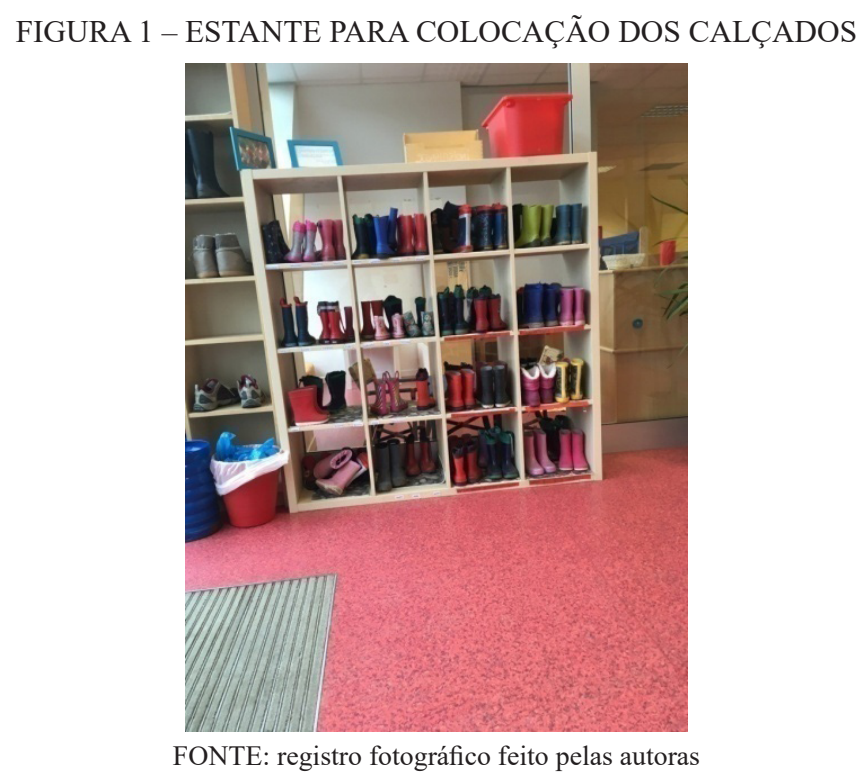


Outra situação cotidiana em que as crianças foram apoiadas a desenvolverem-se autonomamente diz respeito ao momento das refeições:

Durante as refeições são disponibilizados copos e jarras de vidros para as crianças. Mesmo as crianças bem pequenas (18 a 24 meses) são incentivadas a servirem sua própria água. Ao final da refeição, cada criança retira o seu babeiro e o coloca no cesto de babeiros sujos (Caderno de Anotações, 29/01/2018).

A respeito das duas situações descritas, corroboramos com Quadros e Barbosa (2017, p. 49-50), quando argumentam que:

Indubitavelmente, uma importante conquista da pequena infância refere-se à autonomia de crianças nos cuidados pessoais com o próprio corpo. Tomar consciência e ter controle das suas ações, daquilo que o seu corpo produz, de como vestir-se e colocar os seus calçados podem ser "pequenices" aos olhos dos adultos, mas são grandes conquistas na vida de uma criança (destaque das autoras).

As crianças tornam-se gradativamente ainda mais dispostas para explorar as possibilidades de seus corpos e dos espaços aos quais têm acesso. $\mathrm{O}$ encorajamento e o incentivo são fundamentais para que elas aprendam com as suas próprias experiências com ousadia e vivacidade. Saballa e Fochi (2017, p. 26) afirmam que a partir dos desafios e situações ocorridos no dia a dia as crianças têm acesso a diferentes laboratórios. Dentre os quais destacam: "laboratório de cidadania, de participação e emancipação social, cultural e democrática; laboratório para aprender sobre a complexidade e os mistérios do mundo; laboratório da fantasia e da imaginação; laboratório estético e de experimentações diversas".

A partir das observações realizadas nas escolas bolonhesas, é possível afirmar que, de certo modo, elas oportunizavam muitos desses laboratórios:

O pátio era repleto de possibilidades de exploração por parte das crianças (Figura 2). Havia pneus, brinquedos, casas de brinquedo, pás e outras ferramentas para brincarem na horta etc. Uma das casas acessível às crianças tinha um pequeno degrau. Durante o tempo de permanência no pátio, duas meninas subiram e entraram na casinha (Figura 3). Quando quiseram descer, uma delas apresentou dificuldade e chamou uma das professoras para auxiliá-la. A professora, porém, ao invés de simplesmente retirá-la da casa, incentivou-a para que conseguisse descer sozinha sem auxílio. Uma das frases que a professora proferiu foi: "Desça. Conseguiste subir, tenho certeza de que conseguirás descer sozinha". Depois de algumas tentativas, a menina encorajou-se e com um pequeno pulo estava no gramado do pátio (Caderno de Anotações, 30/01/2018). 


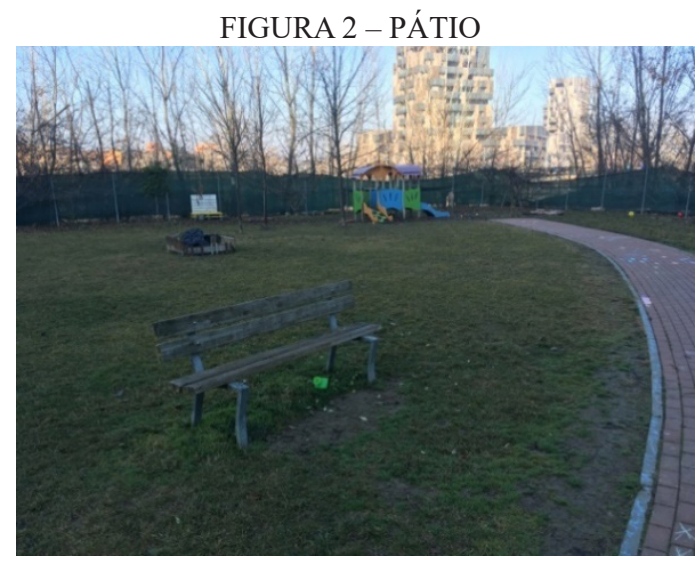

FONTE: registro fotográfico feito pelas autoras

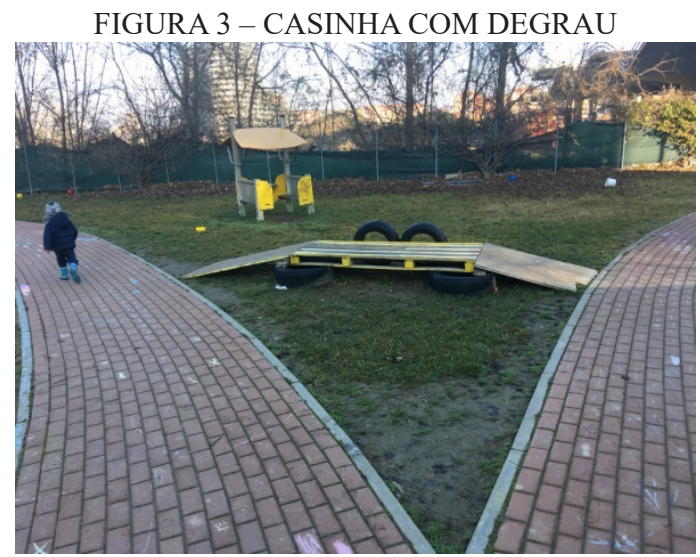

FONTE: registro fotográfico feito pelas autoras

A partir dessa situação, é relevante destacar a relação de confiança estabelecida entre professora e criança: há nesta relação respeito, cuidado e incentivo. Em decorrência dela, também retomamos o entendimento de protagonismo infantil, salientando que ele pode ser considerado como uma possibilidade, mas também como um desejo de que crianças e professoras construam uma relação que vise ao estímulo diário ao sucesso infantil diante da realização de pequenas tarefas realizadas. Nessa direção, é importante tomar o espaço não somente como uma estrutura física, mas como uma gama de relações, sentimentos e emoções em que podem ser produzidos e oportunizados. Nele "é 
importante que a criança se veja constantemente desafiada com novas tarefas e desafios" (BARBOSA e HORN, 2008, p. 77).

Outra situação complexa e desafiadora no cotidiano das crianças pequenas vincula-se ao controle dos esfíncteres:

Algumas crianças da turma de 2 e 3 anos ainda usam fraldas. Quando as professoras sentem algum cheiro decorrente das fezes, elas questionam: "alguém aqui fez 'caca'? É importante que vocês falem quando estão com dor de barriga". Geralmente a criança que está com as fraldas sujas "acusa-se" e é convidada a ir até o fraldário. Lá, a própria criança é incentivada a participar do processo de troca, uma vez que é solicitada a retirar as calças e colocá-las no cesto adequado para as roupas sujas (Caderno de Anotações, 30/01/2018).

Essa situação vai ao encontro do entendimento de Pedagogia do Cotidiano, defendido por Carvalho e Fochi (2017), uma vez que ela emerge de relações, proposições, mediações e descobertas entre os sujeitos docentes e crianças nela envolvidos. Além do que tal situação nos remete à argumentação de Barbosa e Quadros (2017, p. 53), quando afirmam que "Com uma base pedagógica, abre-se espaço para a construção da autonomia no tempo singular de cada um, sem a pressa do mundo dos adultos, mas a partir das necessidades da própria criança $[\ldots . . . "$.

A respeito do processo de controle dos esfíncteres e posterior retirada das fraldas, as mesmas autoras afirmam que são momentos:

[...] de aprendizagem social na vida das crianças em que deve haver respeito à sua autonomia, numa situação que possui interdependência com as culturas locais e requer a presença de um olhar pedagógico. Ao ser vista dessa maneira, torna-se um gesto curricular que une corpo, cognição, cultura e emoção na educação infantil (BARBOSA e QUADROS, 2017, p. 53).

Ademais, a situação descrita anteriormente nos leva a pensar na posição que as docentes assumem no sentido de contribuir para o desenvolvimento e para a conquista da autonomia infantil. De certo modo, as crianças são encorajadas a se observar, a se manifestar e a colaborar no momento de troca de fraldas. A partir do posicionamento das docentes, é possível afirmar que "A criança na mediação com o outro constrói seu mundo por meio do estabelecimento de relações peculiares de confiança, de respeito e de amizade" (MARTINS FILHO e DORNELLES, 2018, p. 8). 
As situações descritas a seguir também se vinculam à importância de oportunizar às crianças condições para realizarem certas tarefas do seu cotidiano:

Era chegada a hora do almoço. Na instituição visitada, as crianças fazem as refeições na própria sala de referência. As merendeiras vão até a sala transportando a comida em um carrinho. Duas ou três crianças ficam responsáveis por auxiliar no processo de organização da sala para que possam usufruir da refeição: nas mesas colocam toalhas, pratos, copos, talheres, jarras com água etc. Em seguida, as merendeiras disponibilizam as porções de comida nas mesas. Depois de organizadas as mesas, as demais crianças são chamadas e cada grupo de crianças é acompanhado por uma educadora. As crianças são servidas, numa primeira vez, pela educadora, porém quando querem repetir são elas quem se servem e são orientadas a servir somente o suficiente (Caderno de Anotações, 31/01/2018).

No pátio havia uma horta, algumas crianças interessaram-se por manuseá-la e cuidá-la. As educadoras, então, disponibilizaram às crianças de $3 / 4$ anos diversas ferramentas (pás, regadores, enxadas etc.) em tamanho pequeno para que pudessem auxiliar no cuidado. Nesta situação, as educadoras muito mais observaram, do que propriamente interviram, ou seja, deixaram que as crianças manuseassem ao seu modo e ao seu tempo as ferramentas, bem como mexessem na horta (Caderno de Anotações, 29/01/2018).

As propostas desenvolvidas com crianças, ainda que simples, precisam estar comprometidas com uma responsabilidade educacional. Ambas as cenas descritas privilegiam a vivência de experiências múltiplas que possibilitam a experimentação e o desenvolvimento de certas habilidades que colaboram para que as crianças vivam autonomamente determinadas situações. Para tanto, é fundamental que a atuação docente esteja centrada na ideia de que as crianças são protagonistas, que podem intervir em todos os momentos da prática pedagógica diária, que devem entrar em cena, que, enfim, devem participar ativamente daquilo que lhes diz respeito e que é proposto na instituição na qual permanecem grande parte de seus dias.

A segunda cena desenrolada na horta presente no pátio da escola leva-nos a pensar sobre a questão da utilização do tempo nas escolas infantis. Estamos habituados a pensar em um tempo produtivo por meio do qual se pode produzir/ fazer muito em pouco tempo. Entretanto, como apontado por Pecoits (2017, p. 174), essa noção de tempo vai de encontro ao que tem se pensado para a escola de educação infantil, uma vez que a calma e o tempo "longo e vazio" permitem que as crianças elaborem suas ideias e conceitos. A esse respeito, Martins Filho e Castro (2018) argumentam que, no âmbito da educação infantil, o entendimento de tempo precisa romper com a lógica adultocêntrica, ele precisa ser flexível e sintonizado com as vontades e com as necessidades das crianças. 
Uma última situação que trazemos relaciona-se ao modo como as salas frequentadas pelas crianças eram ornamentadas:

Um aspecto que chama a atenção é que as salas são decoradas com as próprias produções das crianças (oriundas de propostas com tintas, lápis, argilas etc.). Em sala alguma observou-se decoração decorrente de personagens midiáticos, por exemplo (Caderno de Anotações, 15/01/2018).

Segundo Cruz e Cruz (2017, p. 78), “As experiências que as crianças vivem no contexto da creche ou pré-escola são afetadas pelo conjunto de elementos que configuram esses ambientes". Sendo assim, é importante que a criança se sinta parte do ambiente em que passa grande parte da sua vida. Para isso, fazê-las participar da configuração desse ambiente torna-se um aspecto importante. Nas escolas visitadas a sala referência das turmas não é tomada apenas como um "[...] cenário, mas, certamente, como parte integrante da ação pedagógica" (BARBOSA e HORN, 2008, p. 77).

Malaguzzi (1992, p. 19 apud FARIA, 2007, p. 278) afirma que

Há séculos as crianças esperam ter credibilidade. Credibilidade nos seus talentos, nas suas sensibilidades, nas suas inteligências criativas, no desejo de entender o mundo. É necessário que se entenda que isso que elas querem é demonstrar aquilo que sabem fazer.

E as situações descritas ao longo desta seção analítica demonstram que se tem, pelo menos, tentado proporcionar tal credibilidade na medida em que as crianças têm sido posicionadas como curiosas, produtoras de cultura, como ativa nos processos de experimentação do mundo e como hábil na expressão dos seus sentimentos, pensamentos e emoções (MALAGUZZI, 1999).

\section{Considerações finais}

É fato que estamos vivendo num tempo em que as crianças são vistas, em muitas sociedades, como sujeitos de direitos e ativos nos espaços em que circulam. Mais fortemente a partir de 1989, com a Convenção dos Direitos das Crianças da Organização das Nações Unidas, às crianças foram dadas possibilidades para impor e expor suas vontades e necessidades. 
Em termos curriculares, mais recentemente, uma expressão clara da importância que as crianças têm ocupado na sociedade brasileira é a Base Nacional Comum Curricular (2017), cuja construção deu-se, desde 2014, no âmbito do Ministério da Educação, que contou com a participação e colaboração de professores universitários, professores da Educação Básica e especialistas. Mesmo que haja contradições e disputas de posições e proposições, a terceira e atual versão dessa Base aponta para a necessidade de escutar as crianças sobre todos os processos e ações que lhe concernem, promovendo a sua participação.

Na parte específica desse documento voltado para a Educação Infantil a participação das crianças é colocada como um dos direitos de aprendizagem da etapa da Educação Infantil. A Base define que as crianças devem participar com protagonismo de todos os processos que ocorrem no âmbito das instituições de educação que frequentam, seja nas situações comuns vivenciadas no cotidiano, seja na formulação e discussão sobre as propostas envolvendo os momentos de brincadeiras, ou ainda na escolha dos materiais e na fruição dos diferentes ambientes e tempos que compõem as escolas.

A discussão sobre o currículo para a educação infantil que vem sendo desenvolvida no Brasil tem tomado como referência a maneira como vem sendo proposta a educação de crianças pequenas na Itália. Sendo assim, a própria Base, homologada recentemente, no ano de 2017, apóia-se nessa proposta. Tanto que adota o termo e o entendimento de "Campos de Experiências Educativos" que prima pelo destaque aos pontos de vista e às experiências das crianças.

A educação proposta às crianças nas escolas bolonhesas que pesquisamos vão nessa mesma direção de priorizar as crianças, tal como procuramos evidenciar nas situações analisadas na seção anterior. Ou seja, é possível destacar que tanto a organização do espaço como o modo de atuação docente fortalecem um trabalho pedagógico em que as possibilidades e potencialidades das crianças ganham destaque, sem desconsiderar seus tempos e suas especificidades.

Acionamos, para finalizar, as discussões sobre Pedagogia do Cotidiano desenvolvidas por Carvalho e Fochi (2017, p. 29), que defendem que

[...] o cotidiano, em sua relação com o currículo, é um importante catalizador de experiências. Acreditamos que é a partir da potência do cotidiano (da vida emergente das relações ordinárias estabelecidas no contexto institucional) que podemos pensar no desenvolvimento de potentes ações pedagógicas que propiciem às crianças assumirem o papel de protagonistas na construção dos conhecimentos e de parceiros de jornada com os adultos professores. 
Concluímos reiterando a importância de que, na esfera da educação infantil, sejam oportunizadas e permitidas experiências múltiplas, que estimulem a criatividade, a experimentação, a imaginação e a participação das crianças em seus próprios processos de desenvolvimento e aprendizagem, uma vez que "O aprender da criança não é um fenómeno meramente interior, é uma realidade que depende quer da sua natureza quer da experiência ambiental, no contexto de uma cultura" (OLIVEIRA-FORMOSINHO e FORMOSINHO, 2017, p. 4).

\section{REFERÊNCIAS}

BALDUZZI, L. Nella rete dei servizi per l'infanzia. Tra nidi e nuove tipologie. Ricordando Simonetta Andreoli. Bolonha: CLUEB, 2006.

BARBOSA, M. C. S. Pedagogia da infância. In: OLIVEIRA, D. A.; DUARTE, A. M. C.; VIEIRA, L. M. F. Dicionário: trabalho, profissão e condição docente. Belo Horizonte: UFMG/Faculdade de Educação, 2010. CDROM

BARBOSA, M. C.; QUADROS, V. da S. R. de. As aprendizagens cotidianas: os cuidados pessoais das crianças como gesto curricular. Em Aberto, v. 30, n. 100, p. 45-70, set./dez. 2017. Disponível em: <http://emaberto.inep.gov.br/index.php/emaberto/article/ view/3358>. Acesso em: 29 maio 2018.

BARBOSA, M. C. S.; HORN, M. da G. Projetos Pedagógicos na Educação Infantil. Porto Alegre: Artmed, 2008.

BRASIL. Emenda Constitucional n. 59, de 11 de novembro de 2009. Acrescenta $\S 3^{\circ}$ ao art. 76 do Ato das Disposições Constitucionais Transitórias... Diário Oficial da União, Brasília, DF, 11 nov. 2009. Seção I, p. 8.

BRASIL. Emenda Constitucional n. 53, de 19 de dezembro de 2006. Dá nova redação aos arts. $7^{\circ}, 23,30,206,208,211$ e 212 da Constituição Federal e ao art. 60 do Ato de Disposições Constitucionais. Diário Oficial da União, Brasília, DF, 20 dez. 2006. Seção 1, p. 5-6.

BRASIL. Constituição da República Federativa do Brasil. Brasília, DF: Senado, 1988.

BRASIL. Lei n. 11.114, de 16 de maio de 2005. Altera os artigos $6^{\circ}, 30,32$ e 87 da da Lei 9.394, de 20 de dezembro de 1996, com o objetivo de tornar obrigatório o início do ensino fundamental aos 6 (seis) anos de idade. Diário Oficial da União, Brasília, DF, 17 maio 2005.

BRASIL. Lei n. 11.274, de 6 de fevereiro de 2006. Altera a redação dos arts. 29, 3032 e 87 da Lei 9.394, de 20 de dezembro de 1996, que estabelece as diretrizes e bases da 
educação nacional, dispondo sobre a duração de 9 (nove) anos para o ensino fundamental, com matrícula obrigatória a partir dos 6 (seis) anos de idade. Diário Oficial da União, Brasília, DF, 7 fev. 2006.

BRASIL. Lei n. 8.069, de 13 de julho de 1990. Dispõe sobre o Estatuto da Criança e do Adolescente e dá outras providências. Diário Oficial da União, Brasília, DF, 16 de jul. 1990. Seção 1, p. 13563-577.

BRASIL. Lei n. 9.394, de 20 de dezembro de 1996. Estabelece as diretrizes e bases da educação nacional. Diário Oficial da União, Brasília, DF, 23 dez. 1996.

BRASIL. Lei n. ${ }^{\circ} 12.796$, de 4 de abril de 2013. Altera a Lei n. ${ }^{\circ} 9.394$, de 20 de dezembro de 1996, que estabelece as diretrizes e bases da educação nacional, para dispor sobre a formação dos profissionais da educação e dar outras providências. Diário Oficial da União, Brasília, DF, 5 abr. 2013.

BRASIL. Ministério da Educação. Conselho Nacional da Educação. Diretrizes curriculares nacionais para a educação infantil. Brasília, DF, 2010.

BRASIL. Ministério da Educação. Conselho Nacional da Educação. Referencial curricular nacional para a educação infantil. Brasília, DF, 1998.

BRASIL. Ministério da Educação. Secretaria de Educação Básica. Parâmetros Nacionais de Qualidade para a Educação Infantil. Brasília, DF, 2006. 2v.

BRASIL. Ministério da Educação (MEC). Base Nacional Comum Curricular. Disponível em: $<$ http://portal.mec.gov.br/index.php?option=com_docman\&view=download\&alias=79601-anexo-texto-bncc-reexportado-pdf-2\&category_slug=dezembro-2017-pdf\&Itemid=30192>. Acesso em: 11 mar. 2018.

CAMPOS, M. M. A Educação Infantil como Direito. Insumos para o Debate 2 - Emenda Constitucional n. 59/2009 e a Educação Infantil: impactos e perspectivas. São Paulo. Campanha Nacional pelo Direito à Educação. 2010. p. 8-14.

CAMPOS, R.; BARBOSA, M. C. Obrigatoriedade de matrícula aos 4 anos: ampliação ou recuo do direito? Textura, Canoas, v. 18, n. 36, p. 66-86, jan./abr. 2016. Disponível em: <http://www.periodicos.ulbra.br/index.php/txra/article/view/1627>. Acesso em: 25 fev. 2018.

CARVALHO, R. S. de; FOCHI, P. S. O muro serve para separar os grandes dos pequenos: narrativas para pensar uma pedagogia do cotidiano na educação infantil. Textura, Canoas, v. 18, n. 36, p. 153-170, jan./abr. 2016. Disponível em: <http://www.periodicos.ulbra.br/ index.php/txra/article/view/1949/1458>. Acesso em 18 out. 2018.

CARVALHO, R. S. de; FOCHI, P. S. Pedagogia do cotidiano: reivindicações do currículo para a formação de professores. Em Aberto, Brasília, v. 30, n. 100, p. 23-42, set./dez. 2017. Disponível em: <http://rbep.inep.gov.br/index.php/emaberto/article/view/3498/ pdf>. Acesso em: 25 maio 2018. 
CATARSI, E. Loris Malaguzzi and the municipal school revolution. Children in Europe, v. 6, p. 8-9, 2004.

CORREA, B. Educação infantil e o ensino fundamental: desafios e desencontros na implantação de uma nova política. Educação e Pesquisa, São Paulo, v. 37, n. 1, p. 105 120, jan./abr. 2011.

CRUZ, S. H. V.; CRUZ, R. C. de A. O ambiente na educação infantil e a construção da identidade da criança. Em Aberto, Brasília, v. 30, n. 100, p. 71-81, set./dez. 2017. Disponível em: <http://rbep.inep.gov.br/index.php/emaberto/article/view/3308/pdf>. Acesso em: 26 maio 2018.

FARIA, A. L. G. Loris Malaguzzi e os direitos das crianças pequenas. In: OLIVEIRA-FORMOSINHO, J.; KISHIMOTO, T. M.; PINAZZA, M. A. Pedagogia(s) da Infância: dialogando com o passado - construindo o futuro. Porto Alegre: Artmed, 2007.

FINCO, D.; BARBOSA, M. C.; FARIA, A. L. G. de (Orgs.). Campos de experiência na escola da infância: contribuições italianas para inventar um currículo de educação infantil brasileiro. Campinas: Edições Leitura Crítica, 2015. 276 p.

GADELHA, S. Biopolítica, governamentalidade e educação: introduções e conexões a partir de Michel Foucault. 1. reimp. Belo Horizonte: Autêntica Editora, 2013.

GALARDINI, A. L. Participación. Barcelona: Ocatedro, 2017.

GUIZZO, B. S.; FELIPE, J. Legislação e políticas públicas para a educação infantil. Revista Brasileira de Política e Administração da Educação, Porto Alegre, v. 28, n. 1, p. 629-643, set./dez. 2012.

LAZZARI, A. Early childhood education and care as social innovation tool? Insights from a multi-site case study carried out in Emilia-Romagna Region. Ricerche di Pedagogia e Didattica, Bolonha, v. 3, n. 12, p. 13-39, 2017. Disponível em: <https://rpd.unibo.it/ article/view/7635/7357>. Acesso em: 15 jan. 2018.

LAZZARI, A. The Public Good. Historical and Political Roots of Municipal Preschools in Emilia Romagna. European Journal of Education, v. 47, n. 4, p. 556-568, 2012.

MALAGUZZI, L. História, ideias e filosofia básica. In: EDWARDS, C.; GANDINI, L.; FORMAN, G. As Cem Linguagens da Criança: a abordagem de Reggio Emilia na educação da primeira infância. Porto Alegre: Artmed, 1999. p. 59-104.

MANTOVANI, S.; MUSATTI, T. New educational provision for young children in Italy. European Journal of Psychology of Education, v. 11, p. 119-128, 1996.

MARTINS FILHO, A. J.; CASTRO, J. S. de. Avaliação na e da Educação Infantil: avaliação de Contexto. Pro-posições, Campinas, v. 29, n. 2, p. 11-23, maio/ago. 2018. Disponível em: <http://www.scielo.br/pdf/pp/v29n2/0103-7307-pp-29-2-0011.pdf>. Acesso em 10 out. 2018. 
MARTINS FILHO, A. J.; DORNELLES, L. V. Apresentação. In: MARTINS FILHO, A. J.; DORNELLES, L. V. (Orgs.). Lugar da criança na escola e na família: a participação e o protagonismo infantil. Porto Alegre: Editora Mediação, 2018. p. 7-10.

MOSS, P. Introduzindo a política na creche: a educação infantil como prática democrática. Psicologia USP, São Paulo, v. 20. n. 3, 417-436. Disponível em: <http:/www.scielo.br/ pdf/pusp/v20n3/v20n3a07.pdf>. Acesso em: 19 fev. 2015.

MOSS, P. Why can't we get beyond quality? Contemporary Issues in Early Childhood. London, v. 17, p. 8-18, march 2016.

OLIVEIRA-FORMOSINHO, J. Pedagogia(s) da infância: reconstruindo uma práxis de participação. In: OLIVEIRA-FORMOSINHO, J. et al. (Orgs.). Pedagogia(s) da Infância: dialogando com o passado, construindo o futuro. Porto Alegre: Artmed, 2007, p. 13-36.

OLIVEIRA-FORMOSINHO, J.; FORMOSINHO, J. Pedagogia-em-Participação: a documentação pedagógica no âmago da instituição dos direitos da criança no cotidiano. Em Aberto, Brasília, v. 30, n. 100, p. 115-130, set./dez. 2017. Disponível em: <http:// rbep.inep.gov.br/index.php/emaberto/article/view/3391/pdf>. Acesso em: 27 maio 2018.

PECOITS, S. da S. Os adultos possuem relógios, as crianças possuem tempo. Em Aberto, Brasília, v. 30, n. 100, p. 173-176, set./dez. 2017. Disponível em: <http://emaberto.inep. gov.br/index.php/emaberto/article/view/3304/pdf>. Acesso em: 20 jul. 2018.

ROSEMBERG, F. A educação pré-escolar obrigatória: versão preliminar. In: REUNIÃO ANUAL DA ANPEd, 32, 2009, Caxambu/MG. Trabalhos... Caxambu: ANPED, 2009. mimeo.

ROSEMBERG, F. Políticas públicas e qualidade na Educação Infantil. In: OLIVEIRA, M. O.; RIBEIRO, M. I. S. (Orgs.). Educação Infantil: os desafios estão postos, e o que estamos fazendo? Salvador: Sooffset, 2014.

SUBRAMANIAN, M. Rethinking play: A postcolonial feminist critique of international early childhood education policy. International Journal of Educational Development, v. 45 , p. 161-168, 2015.

TAGGART, B.; SYLVA, K.; MELHUISH, E.; SAMMONS, P.; BLATCHFORD, I. O poder da pré-escola: evidências de um estudo longitudinal na Inglaterra. Cadernos de Pesquisa, São Paulo, v. 41, n. 1, p. 68-99, jan./abr. 2011.

ZUCCOLI, F. G.; INFANTINO, A. Curriculum zero-seis: conhecimentos feitos de descobertas e reflexões. Revista Linhas, v. 19, n. 40, p. 16-37, maio/ago. 2018.

Texto recebido em 08 de janeiro de 2018.

Texto aprovado em 31 de janeiro de 2018. 